\title{
"Investigative Science Learning Environment: Using the processes of science and cognitive strategies to learn physics”
}

Eugenia Etkina, Rutgers University, 10 Seminary Place, New Brunswick, NJ 08901

etkina@rci.rutgers.edu

Alan Van Heuvelen, The Ohio State University

\begin{abstract}
Does reading fifteen textbook chapters, listening to one lecturer, doing prescribed labs, answering someone else's questions, and solving well-defined problems resemble in any way a five-month schedule of activities for a person in a science related field in the $21^{\text {st }}$ century workplace? Several recent studies concerning the knowledge and skills needed in the workplace indicate that there is a serious mismatch between traditional physics instruction and the needs of the workplace. Even active engagement methods (such as used for many years by the authors) do not really satisfy the needs of the workplace. In this paper, we describe briefly an Investigative Science Learning Environment (ISLE) introductory physics learning system that attempts to replicate more closely the processes used in the real world of science and engineering. We hope that ISLE students' learning better meets the needs of the workplace. We will describe the method, including goals of the instruction, techniques used to assess the achievement of these goals and preliminary results of this assessment from courses taught by different instructors.
\end{abstract}

\section{Introduction}

John Amos Comentus (1592-1670) asked: "How many of those who undertake to educate the young appreciate the necessity of first teaching them how to acquire knowledge?” John Dewey responded to this rhetorical question 300 years later by saying that science education has failed because it "has been so frequently presented just as so much ready-made knowledge, so much subject-matter of fact and law, rather than as the effective method of inquiry into any subject matter."1 Recent studies from the workplace support these comments by Comentus and Dewey and ask for education in science and engineering that resembles the processes scientists use to acquire and productively use knowledge. The U.S. Department of Labor, ${ }^{2}$ the ABET engineering accreditation organization, ${ }^{3}$ the National Science Foundation, ${ }^{4}$ and the American Institute of Physics ${ }^{5}$ studied knowledge and skills that the real world workplace wants in its $21^{\text {st }}$ century employees. These reports suggest that graduates should know how to learn, be able to use the processes of scientific inquiry, be able to use expert-like strategies to solve real world problems, and be able to design investigations, products and devices. Many educational approaches address some of these needs. These are described in the works of McDermott et $\mathrm{al}^{6}$, Laws, ${ }^{7}$ Hestenes, ${ }^{8}$ Duchovich et al, ${ }^{9}$ Arons, ${ }^{10}$ Albe, ${ }^{11}$ and Goldberg. ${ }^{12}$ The target audiences and the methods used to achieve the goals of the instruction in these programs vary.

Investigative Science Learning Environment (ISLE) is a new introductory physics learning system which makes a conscious attempt to help students better acquire the skills needed in the real world as they learn physics. ISLE students learn physics by repeatedly using processes that physicists use to construct and evaluate physics knowledge. Students later apply this knowledge to design their own investigations and products. In this paper we will describe the main features of ISLE, provide a specific example of a unit and of some assessment activities that have been used to evaluate ISLE, and report on the results of ISLE classes taught by different instructors.

\section{What is ISLE?}

The first feature of ISLE is that students learn physics through a scientific investigation cycle that they follow for each conceptual unit. The instructor in ISLE does 
not provide students with physics concepts to study or practice and then illustrate presented concepts with packaged demonstrations. Instead, students construct and test the concepts themselves. For each conceptual unit students observe carefully selected physical phenomena (experiments) and then in a small group construct their own explanation for the phenomena. After the groups share their explanations, they then design testing experiments to determine if the explanations work, identify physical quantities and find relationships between them empirically or by derivations using prior knowledge. Then students design experiments to test the relationships and finally apply these concepts to unfamiliar phenomena and problems. In short, students use processes that scientists use to acquire and to test conceptual knowledge. They follow the same cycle for each unit and continuously reflect on "how they know what they know." Thus students become familiar with the epistemology of the scientific community.

The second feature of ISLE is that students master the concepts that they devised by using various thinking and learning strategies. Special tasks are designed to help students construct images of physics ideas using concrete physical representations ${ }^{13}$ such as motion diagrams, energy bar charts, force diagrams, and ray diagrams before they start using mathematics. Conceptual thinking using concrete representations is one strategy that scientists use to comprehend new knowledge and to apply it. Students also use multiple representations of processes ${ }^{14}$ (including simultaneous representations of simulated processes ${ }^{15}$ ). They apply concepts to real concrete phenomena, ${ }^{16}$ and use physics concepts to solve ill-defined problems that require analysis, synthesis, and evaluation.

These two features of ISLE help students to organize knowledge around a small number of elements in each conceptual unit of physics knowledge, such as phenomena, models, physical quantities, laws, and limitations. They also organize the knowledge unit around a small number of concepts and learn cues for accessing useful knowledge for particular tasks. Thus students acquire a more expert-like deep knowledge structure.

ISLE helps students acquire the skills of learning how to learn-content independent general skills. They construct the concepts by actively participating in learning, experimentally testing their ideas, learning to represent concepts in multiple ways, and developing strategies for organizing and accessing knowledge.

\section{How to implement this approach}

Each major unit in the learning system follows a cycle: observations - qualitative explanations - physical representation testing - quantitative explanations - multiple representations - testing - applications. At two testing stages students revisit the observation or explanation stages if their predictions do not work. Consider an example.

\section{Example: wave optics}

Observations (there are no explanations by the instructor before these observations, they can be conducted in a lecture or a lab depending on the structure of the course). After studying geometrical optics where students construct the idea that light propagates along straight lines through a medium, students observe what happens when laser light hits an aperture with two small slits and then reflects off a screen beyond the aperture. They observe that the patterns on the screen differ when the slits are big and when they are small.

Explanation To explain their observations, students need to find the most important features in the patterns. The big slits seem to fit into their previous knowledge about propagation of light while the small ones do not. Students, already familiar with superposition of mechanical waves, 
eventually recognize the interference patterns and offer a wave-based explanation for the phenomenon.

Testing: Students test their qualitative model of light as a wave by predicting what happens if light goes through slits separated by a different distance. They then perform the experiment.

Physical quantities and law: Students quantify their explanation and devise a formula that relates the location of the bright spots, the distance to the screen and the distance between the slits. Using an analogy with mechanical waves students devise a relationship. They do not necessarily devise the conventional formula for the maxima ( $d$ $\sin \theta=n \lambda)$, but their mathematical expressions are equivalent to it.

Testing: Students are asked to test if the relationship they derived works and decide what feature of light is related to the wavelength. They usually connect the wavelength with color, and then test this idea by predicting that the bright spots would be separated differently if the laser had a different color (green lasers). They also predict what they will see if they use a system with many tiny slits (a diffraction grating). They perform the experiments to see if their predictions work.

Applications: As an application of the wave idea students are asked to design an instrument that allows them to decide if light emitted by different sources has the same composition. This task makes them design a simple spectrometer.

\section{Assessment}

We have used several traditional and non-traditional instruments to monitor students' progress.

Formative Assessment: We use Weekly Reports $^{12}$ as a formative assessment instrument that simultaneously teaches students to summarize what they learned and how they learned it, to ask questions, and to predict how they will be tested.
A new student experiment design process is also used-Concept Testing Experiments. Students submit in paper or on the web before the next lecture their proposed experiment along with the physics analysis that can be used to make a prediction about the outcome of the experiment. Students perform the experiments in lab or the professor chooses some experiments for the next lecture. Later, students' designs are used as group problems as parts of exams. Student groups evaluate the feasibility and "physics correctness" of some of the proposed testing experiments designed by their peers.

Summative Assessment: Tests such as the Force Concept Inventory Test (FCI), the Force and Motion Conceptual Evaluation, the Test of Understanding of GraphsKinematics (TUG-K), the Mechanics Baseline Test, and the Conceptual Survey of Electricity and Magnetism (CSEM) allow us to compare ISLE students with students nationwide in terms of conceptual understanding and problem solving. A new type of question-a proof question-was developed for the exams. An example from electromagnetism: "Your younger brother is taking high school physics and has problems with static electricity. How can you convince him that conductors have freely moving charges inside them and insulators do not?” A successful answer might involve a description of an experiment in which a metal rod is used to charge an uncharged electroscope by connecting it to a charged one, whereas a plastic rod does not allow this charge transfer.

\section{Preliminary results}

Two professors used the ISLE system for the first quarter of calculus-based physics for Freshmen Engineering Honors students at Ohio State University. The gfactor gain [(posttest score - pretest score $) /(100$ - pretest score)] on the FCI in Fall 2001 was 0.56 (the same for AVH with 100 students and for a self proclaimed 
former traditional lecturer who used ISLE with 100 students). Xueli Zou used ISLE in her first semester of teaching at California State University-Chico and had a 0.45 gain on the FCI test in a regular calculus-based physics course.

ISLE was used for two quarters by three different OSU professors in the electricity and magnetism part of the Freshmen Engineering Honors program. Two of them had never taught a lecture section before. The average posttest score for the three classes on the CSEM ranged from 69-74 percent (traditionally taught students in the electricity and magnetism part of calculusbased physics at OSU and at other universities score 45-50 percent).

Analysis of students' Weekly Reports, proof questions on the exams, concept testing experiment designs, and their evaluation of peer concept testing experiments helped us follow students' development of higher level thinking skills, such as questioning, synthesis, and evaluation. The best improvements were in evaluation and design (which require synthesis skills).

The method has been used in classes for pre-service high school physics teachers and for pre-service elementary science teachers. The method has been used in high school physics and in elementary science instruction. (An urban $4^{\text {th }}$ grade class with 100 percent minority students being taught with ISLE had one of the highest scores on the $\mathrm{NJ} 4^{\text {th }}$ grade science competency test.)

\footnotetext{
${ }^{1}$ John Dewey on Education: Selected Writings, ed. by R.D. Archambault, Random House, New York, 1964, p. 182.

${ }^{2}$ A.P. Carnevale, L.J. Gainer \& A.S. Meltzer, Workplace Basics: The Essential Skills

Employers Want (Jossey-Bass Publishers, San Francisco, 1990).

${ }^{3}$ ABET criteria 2000 documents can be downloaded from the ABET web site:http://www.abet.org/downloads.htm. 4 "Shaping the Future: New Expectations for Undergraduate Education in Science,
}

Mathematics, Engineering, and Technology". http://www.ehr.nsf.gov/ehr/due/documents/revie w/96139/start.htm.

${ }^{5}$ D. Rosdil, "What are Masters Doing?” AIP Statistics Div., Pub.No. R-398.1, Sept. 1996.

${ }^{6}$ L. C. McDermott, “Combined Physics Course for Future Elementary and Secondary School Teachers,” Am. J. Phys. 42, 668 - 676 (1974); and "What we teach and what is learned: closing the gap,” Am.J.Phys. 59, 301-315 (1991).

${ }^{7}$ P. Laws, "Calculus-Based Physics Without Lectures," Physics Today 44 (12), 24-31 (1991)

${ }^{8}$ D. Hestenes, "Toward a Modeling Theory of Physics Instruction,” Am J. Phys. 55, 440-454 (1987).

${ }^{9}$ R. J Duchovic, D. P. Maloney, A. Majumdar, R. S. Manalis, "Teaching Science to the Nonscience Major - an Interdisciplinary Approach”, JCST, February, 258 - 262, (1998). ${ }^{10}$ A. A. Arons, "Guiding Insight and Inquiry in the Introductory Physics Laboratory," The Physics Teacher 31, 278-282 (1993).

${ }^{11}$ A. Elby, "Helping physics students learn how to learn,” Am. J. Phys. 69, 554-564 (2001).

${ }^{12}$ http://cipsproject.sdsu.edu/.

${ }^{13}$ A. Van Heuvelen, "Overview Case Study Physics,” Am. J. Phys. 59, 898-907 (1991).

${ }^{14}$ A. Van Heuvelen \& X. Zou, "Multiple Representations of Work-Energy Processes," Am. J. Phys., 69, 184-193 (2001).

${ }^{15}$ A. Van Heuvelen and E. Etkina, "Using Multimedia Interactively in an Introductory Epistemological Physics Learning System,” Proceedings of the Computers and Advanced Technology in Education (CATE 2000) IASTED International Conference, Cancun, May 25, 2000.

${ }^{16}$ P. Heller and M. Hollabaugh, "Teaching Problem Solving Through Cooperative Grouping. Part 2: Designing Problems and Structuring Groups,” Am. J. Phys. 60, 637-644 (1992). 